\title{
DOENÇA NEONATAL ASSOCIADA AO ESTREPTOCOCO DO GRUPO B
}

\author{
NEONATAL DISEASE ASSOCIATED WITH GROUP B STREPTOCOCCUS
}

\author{
Tâmara Dayse F. Barbosa, Lindinalva de Freitas Lima, Renata Carneiro Ferreira Souto \\ Pontifícia Universidade Católica de Goiás - PUC
}

\section{Abstract}

Group B Streptococcus (GBS) or Streptococcus agalactiae, are bacteria that colonize the gastrointestinal and genitourinary tract of humans. In pregnant women the presence of this microorganism varies between $3 \%$ and $41 \%$ and its clinical importance is associated with the vertical contamination of the neonates of colonized parturients, in addition to the possible clinical complications. The present study aims to encompass microbiological and preventive aspects of perinatal streptococcal disease and contribute to the applicability of this knowledge in the Brazilian health system. As a method, the literature review was adopted based on articles published between 1996 and 2016. The colonization of the pregnant woman by GBS is closely associated with preterm delivery and the possibility of serious infections in the newborn. In research conducted in the Northeast, South and Southeast regions of Brazil, the rate of isolation of GBS in pregnant women was $11.2 \%$ to $21.6 \%$. Diagnosis is often difficult and the strategies available to decrease the frequency of this infection are chemoprophylaxis, immunization not yet available in Brazil, delivery channel antisepsis, and collection and culture of anal and vaginal secretions collected between the 35th and 37th weeks Gestation. The verification of cases and analysis of maternal infection rates may contribute to the adoption of more effective preventive measures aimed at reducing infection in newborns, sequelae or even death.

\section{Resumo}

O estreptococo do Grupo B (EGB) ou Streptococcus agalactiae, são bactérias que colonizam o trato gastrointestinal e geniturinário de humanos. Em gestantes a presença deste micro-organismo varia entre $3 \%$ a $41 \%$ e sua importância clínica está associada à contaminação vertical dos neonatos de parturientes colonizadas, além das possíveis complicações clínicas. O presente estudo tem como objetivo englobar aspectos microbiológicos e preventivos da doença estreptocócica perinatal e contribuir para a aplicabilidade destes conhecimentos no sistema de saúde brasileiro. Como método, adotou-se a revisão bibliográfica com base em artigos publicados entre os anos de 1996 e 2016. A colonização da gestante pelo EGB está intimamente associada ao parto prematuro e à possibilidade de ocorrência de infecções graves no recém-nascido. Em pesquisas realizadas nas regiões Nordeste, Sul e Sudeste do Brasil, a taxa de isolamento do EGB em gestantes foi de $11,2 \%$ a $21,6 \%$. O diagnóstico muitas vezes é difícil e as estratégias disponíveis para diminuir a frequência desta infecção são quimioprofilaxia, a imunização, ainda não disponível no Brasil, antissepsia do canal de parto e coleta para cultura de secreção vaginal e anal colhida entre a 35 e 37a semana de gestação. A verificação dos casos e análise das taxas de infecção materna poderá contribuir para adoção de medidas preventivas mais eficazes, visando diminuir a infecção em recém-nascidos, sequelas ou mesmo óbito.

Palavras chave: Streptococcus agalactiae; Nascimento Prematuro; Recém-nascido. 
Introdução

O estreptococo do Grupo B (EGB) ou Streptococcus agalactiae, são bactérias que colonizam o trato gastrointestinal e geniturinário de humanos, foi descrito pela primeira vez por Nocard e Mollereau, em 1887, com o nome de "Streptococcus da mastite", sendo denominado posteriormente, como $S$. agalactiae, por Lehmann e Neumann, em $1896^{1}$.

Em 1933, Rebecca Craighill Lancefield desenvolveu um método sorológico para diferenciação dos estreptococos beta hemolíticos, o qual se baseia nas características antigênicas do carboidrato $C$ da parede celular. Tomando como base esse polissacarídeo, os estreptococos foram divididos em 20 grupos denominados por letras maiúsculas do alfabeto A, B, C, D, E, F, G, H, K, L, M, N, O, P, Q, R, S, T, U e V. Em 1934, diferenciou sorologicamente o estreptococo hemolítico bovino, o $S$. agalactiae, classificando-o como pertencente ao grupo B, assim o S. agalactiae ficou conhecido como o Estreptococo do grupo B de Lancefield ${ }^{2,3}$.

Apresenta morfologia de coco Gram positivo disposto em cadeias ou aos pares, algumas vezes ovoides, com tamanho de 0,6 a 1,2 $\mu \mathrm{m}$ de diâmetro. É imóvel, anaeróbio facultativo, homofermentadores, catalase, oxidase e teste de solubilidade à bile negativo, apresenta positividade ao teste de CAMP, hidrólise do hipurato, fosfatase alcalina, acidificação da glicose, glicerol, maltose; ribose e sacarose positivas, possuem resistência aos antimicrobianos: bacitracina, sulfametoxazoltrimetoprime e optoquina e não resiste ao calor de 60 으 por 30 minutos $^{1,4}$.

Facilmente cultivável em ágar sangue, o S.agalactiae apresenta colônias pequenas de cor alaranjada, amarela ou vermelho tijolo, cores estas favorecidas pelo cultivo anaeróbico, em meio contendo amido, inibidores da síntese de folatos, como o metotrexato, e pH superior a 7,3. A hemólise é variável segundo a cepa, sendo possível observar hemólise alfa, frequentemente formando duas zonas de hemólise, estreita zona de hemólise beta, que pode aparecer opaca, ou mesmo ausência de hemólise. Baseado na cápsula de polissacarídeos possui nove sorotipos, que variam de acordo com os determinantes antigênicos presentes em sua superfície celular $^{1,5}$.

A prevalência destes micro-organismos em gestantes é, a nível mundial, com prevalência variando de $3 \%$ a $41 \%{ }^{6,7,8}$. Já no Brasil, alguns autores encontraram taxas de colonização entre $5 \%$ e $25 \%^{7,9,10}$. Sua importância clínica ocorre devido a possível contaminação vertical dos neonatos de parturientes colonizadas, podendo causar sérias consequências tais como pneumonia, sepse neonatal, meningite e óbito neonatal. A mortalidade neonatal no Brasil constitui um grave problema de saúde pública, pois aqui ainda não existem estratégias de prevenção e tratamento para diminuir os casos de infecção de recém-nascidos pelo EGB ${ }^{11}$.

Assim, o objetivo do trabalho foi englobar aspectos microbiológicos e preventivos da doença estreptocócica perinatal e contribuir para a aplicabilidade destes conhecimentos no sistema de saúde brasileiro. Há uma necessidade de adoção de políticas de saúde, visando reduzir a transmissão vertical deste agente bacteriano, as quais devem ser elaboradas com base em conhecimentos sobre a prevalência, fatores de risco de colonização e as características fenotípicas do EGB.

\section{Metodologia}

Esta revisão bibliográfica constitui um estudo observacional descritivo, tendo sido realizada a partir de artigos científicos publicados em periódicos e revistas especializadas, livros de microbiologia, clínica médica, dissertações e teses que abordam assuntos relacionados à infecção materna e neonatal pelo EGB. As bases consultadas foram Pubmed/Medline, Scielo, Lilacs, periódicos da Capes, teses da Universidade de São Paulo, entre outros, sendo a busca realizada nos periódicos publicados entre os anos de 1996 e 2016, utilizando os descritores Streptococcus agalactiae, nascimento prematuro e recém-nascido.

A pesquisa dos artigos ocorreu de fevereiro de 2016 a junho de 2016, sendo que foram selecionadas fontes escritas tanto em português quanto em inglês. Para inclusão destes textos no estudo foram selecionados e revisados os artigos relacionados ao assunto Streptococcus agalactiae em gestantes além de diretrizes nacionais e internacionais sobre a conduta e diagnóstico laboratorial. Foram rejeitados os artigos publicados antes de 1996 e os que não abordavam o estreptococo do grupo B como o agente principal de infecção na gestante. Foram analisados 151 artigos, sendo que destes, 60 foram excluídos por terem sido publicados antes de 1996 e dos 91 restantes, apenas 35 apresentavam informações sobre o agente 
patogênico na população em estudo, além dos descritores utilizados para a seleção inicial.

\section{Resultados e discussões}

A maior importância já registrada do EGB em perinatalogia ocorreu na década de 70 nos Estados Unidos, quando relatórios o apontaram como o maior causador de sepse neonatal, sendo responsável por cerca de 7.500 novos casos a cada ano, nas décadas de 80 e $90^{5}$. A prevalência da colonização do EGB em gestantes e em neonatos tem sido vastamente estudada nos EUA e Europa. Porém, na América Latina há poucos dados referentes à epidemiologia desta infecção neste grupo específico ${ }^{7}$.

No Brasil a taxa de isolamento do EGB encontrada em gestantes e neonatos variou entre $11,2 \%$ a $21,6 \%$, sendo que nestes, as coletas foram realizadas na região anal e vaginal entre a 35ạ e 37ạ semana de gestação, assim como preconizado pelo Centers for Disease Control and Prevention (CDC) $7,12,13,14$.

Em um estudo realizado na cidade de Ribeirão Preto no Estado de São Paulo, em 1997, houve o relato de uma prevalência bem significativa de Sepse Neonatal (SN) provocada pelo $E G B$, sendo que $37,8 \%$ dos casos de infecção foram confirmados ${ }^{15}$. Miura e Martin ${ }^{16}$ também $^{2}$ demostraram em um estudo feito em Porto Alegre - RS, que o EGB foi um dos patógenos mais importantes, associados aos casos de sepse de início precoce em recém-nascidos (RN), acometendo $1 / 1000$ nascidos vivos ${ }^{16}$. No ano de 2007, em uma maternidade da cidade de Manaus - AM, um estudo demonstrou que o EGB foi o agente mais prevalente em hemoculturas realizadas de $\mathrm{RN}$, onde 5,3\% (16/302) apresentaram positividade ${ }^{17}$. Estas variações nas taxas estão associadas à realização da coleta e do diagnóstico corretos pois, ausência da pesquisa do EGB em gestantes pode justificar a ocorrência de sepse neonatal, pelo micro-organismo, colocando em risco a vida do recém-nascido ou mesmo gerando danos futuros à criança.

Para que o exame de detecção deste microorganismo tenha alta sensibilidade e especificidade, é obrigatório que a coleta da amostra ano-vaginal seja feita entre a 35a e 37ạ semanas de gestação. Primeiramente é realizada a coleta no canal vaginal com swab sem uso de espéculo.

Esta amostra deve ser colhida da vagina inferior introduzindo o swab cerca de dois centímetros, fazendo movimentos giratórios por toda a parede vaginal. Para a coleta anal, outro swab deve ser introduzido cerca de $0,5 \mathrm{~cm}$ no esfíncter anal ${ }^{18}$. Em seguida, deve ser realizada a identificação das amostras (vaginal e anal) e as mesmas acondicionadas em meio de transporte adequado, sendo geralmente utilizado o meio Stuart $^{19}$.

O uso de meios de transporte é importante, principalmente, em locais onde não é possível a realização do procedimento laboratorial de imediato, pois o mesmo mantém a viabilidade do $E_{G B}{ }^{20}$. Os isolados do EGB podem permancer viáveis durante vários dias no meio de transporte à temperatura ambiente, entretanto a sensibilidade de detecção do mesmo diminui no período de um a quatro dias, se estes estiverem expostos a altas temperaturas, ou pode aumentar, se a amostra for armazenada a 4 으 antes da cultura e processada dentro de 24 horas após a coleta ${ }^{21}$.

Antes de realizar a inoculação nos meios convencionais ideais para cultivo do EGB, recomenda-se utilizar caldos para enriquecimento, como o caldo Todd-Hewitt suplementado com gentamicina $(8 \mu \mathrm{g} / \mathrm{ml}$ ) e ácido nalidíxico (15 $\mathrm{\mu g} / \mathrm{ml}$ ) (caldo TransVag) ou com colistina $(10 \mu \mathrm{g} / \mathrm{ml})$ e ácido nalidíxico (15 $\mu \mathrm{g} / \mathrm{ml}$ ) (Caldo Lim) e Caldo chromID Biphasic. Estes caldos de enriquecimento seletivo podem conter substratos cromogênicos que proporcionam uma alteração na cor e na configuração do EGB beta-hemolítico, além disso, estes caldos podem facilitar a sua identificação, pois estes melhoraram substancialmente a detecção em baixas taxas de colonização ${ }^{20}$.

Já os meios convencionais, utilizados para a identificação do EGB, são o ágar sangue subcultivo, ágar granada, que é um meio de cultura específico para identificação do EGB, o qual utiliza um pigmento poliênico vermelho (granadaene), que diferencia as colônias do EGB pela cor. Presunção pelo teste CAMP, que consiste na detecção desse fator, o qual aumenta a ação lítica da $\beta$-hemolisina do Staphylococcus aureus sobre as hemácias do ágar sangue, formando uma zona de hemólise sinérgica, que apresenta forma de seta ou meia-lua quando essas bactérias são inoculadas perpendicularmente no meio, produzida pela ação da esfingomielinase ( $\beta$-toxina) dos Staphylococcus e a ceramida ( $\mathrm{N}$-acetilesfingosina), uma proteína de ligação do $S$. agalactiae $^{4}$. Além desses meios é possível realizar testes sorológicos para a detecção do antígeno do grupo B, com a utilização de antissoros específicos $^{22}$. 
Mais recentemente, tornaram-se disponíveis ágares cromogênicos que sofrem alteração de cor na presença de colônias betahemolíticas e não hemolíticas do EGB. Tal como com os caldos de enriquecimento pigmentados, estes ágares cromogênicos podem facilitar a detecção do EGB beta-hemolítico, mas a maioria não irá detectar cepas não hemolíticas. Além disso, foram desenvolvidas técnicas mais rápidas para identificar o EGB diretamente a partir do caldo de enriquecimento ou após a subcultura, incluindo testes de amplificação de ácidos nucleicos (NAAT), tais como reação em cadeia da polimerase $^{20}$. Estes diversos métodos de diagnóstico disponíveis para isolamento e identificação correta do EGB, principalmente em gestantes, influencia positivamente no desfecho da gestação quando comparado às possibilidades de complicações associadas ao micro-organismo.

A infecção pelo EGB é considerada um importante problema na saúde pública, podendo estar associada à pneumonia, sepse neonatal, meningite e óbito neonatal, é mais comum que outras doenças já rastreadas rotineiramente no pré-natal $^{23,24}$. Trata-se de um dos mais importantes agentes ocasionais de infecções neonatais graves ${ }^{25}$. A infecção dos RN por esta bactéria resulta da transmissão vertical (mãefeto), seja por via ascendente, através das membranas íntegras ou no momento do parto, seja por contato do micro-organismo com tecidos fetais ou ainda por aspiração de secreções vaginais pelo feto. A taxa de colonização em recém-nascidos de mulheres colonizadas é de, aproximadamente $50 \%$, independentemente da via de parto ${ }^{11}$.

Após a aspiração do líquido amniótico e/ou fluido vaginal infectado, o pulmão do RN torna-se o foco inicial da infecção pelo $\mathrm{EGB}^{26}$. Logo depois que esta bactéria penetra nos pulmões, ocorre o recrutamento da resposta imunológica com a tentativa de eliminá-la, porém o neonato não possui quantidade de macrófagos suficientes para fagocitar e eliminar a bactéria, pois seu sistema complemento ainda se encontra deficiente com quimiotaxia reduzida dos neutrófilos, além da presença da cápsula que envolve esta bactéria, que também limita a ação dos macrófagos favorecendo, assim, a disseminação da bactéria. Desta forma o EGB sobrevive por até 48 horas nos pulmões, podendo passar para a corrente sanguínea (sepse) e disseminar, infectando outros tecidos ${ }^{2}$.

Já a sepse neonatal é uma síndrome clínica grave, que acomete principalmente os recémnascidos pré-termo com peso de nascimento inferior a $1.500 \mathrm{~g}$. Sendo considerado um dos quadros infecciosos mais frequentes neste período, caracterizado por sinais de infecção em todo o organismo, juntamente com a presença de bactérias no sangue no primeiro mês de vida $^{27,28}$.

A cada ano, aproximadamente 30 milhões de recém-nascidos são acometidos e, destes, cerca de 1 a 2 milhões vão a óbito ${ }^{29}$. No Brasil, estima-se que cerca de $60 \%$ da mortalidade infantil ocorra no período neonatal, sendo que a sepse neonatal é uma das principais causas, conforme dados nacionais disponibilizados no Sistema de Informação de Mortalidade (SIM). Classificada de acordo com o tempo, a sepse pode ser considerada precoce, cujas manifestações clínicas ocorrem em até 72 horas após o nascimento ou tardia, cujo sintomas aparecem após as 72 horas $^{27}$.

Em relação à meningite, há uma variedade de fatores de virulência associados ao EGB, que favorecem a sua adesão e invasão a partir da barreira hematoencefálica, causando a meningite. Os casos provocados pelo EGB podem acometer aproximadamente $5 \%$ a $15 \%$ dos RN, podendo causar sequelas neurológicas graves ou mesmo evoluir para o óbito, no segundo dia de vida $^{26,30}$

O diagnóstico das infecções no RN muitas vezes é difícil, uma vez que as manifestações clínicas são inespecíficas e podem ser confundidas com outras doenças próprias dessa faixa etária, portanto, é muito importante a realização de exames laboratoriais como: hemocultura, que é considerada o padrão ouro para detecção do agente, cultura de líquor, cultura de aspirado traqueal, hemograma, proteína $\mathrm{C}$ reativa e Velocidade De Hemossedimentação (VHS). A dosagem de algumas citocinas, particularmente Interleucina- 6 (IL-6), Fator de necrose tumoral- $\alpha$ (TNF- $\alpha$ ) e Interleucina-1 $\beta$ (IL-1 $\beta$ ), também pode ser feita, entretanto o valor elevado e a indisponibilidade desses kits para rotina laboratorial acabam limitando o uso desses testes para o diagnóstico da sepse neonatal precoce. A associação dos dados clínicos com os resultados dos exames possibilita concluir o diagnóstico, além de determinar a conduta terapêutica ${ }^{27,30}$.

Devido à grande incidência e a gravidade das infecções causadas pelo EGB o Centers for Disease Control and Prevention (CDC), o American College of Obstetricians and Gynecologists (ACGO) e a American Academy of Pediatrics (AAP) publicaram, em 1996, o primeiro guia para prevenção da doença estreptocócica 
perinatal precoce, que foi revisado e modificado em $2002^{5,32}$. Assim, existem três estratégias que podem ser utilizadas para a prevenção da colonização pelo EGB, como a imunização, a antissepsia do canal do parto e a profilaxia com antibióticos intraparto (quimioprofilaxia) ${ }^{31}$.

A imunização é uma estratégia avançada, mas não se encontra disponível no Brasil. As vacinas utilizadas para a prevenção do EGB foram analisadas por ser uma ferramenta que poderão reduzir a colonização materna e prevenir a infecção do recém-nascido, eliminando a necessidade de rastreamento e do uso de antibióticos intraparto. Essa vacina tem como princípio, induzir a produção de anticorpos específicos contra a cápsula polissacarídea do EGB. Investigações estão sendo realizadas e têm demonstrado boa tolerância e imunogenicidade. Entretanto, o maior problema está na dificuldade de desenvolver conjugação das diferentes cepas do estreptococo, solucionando isso, a vacina poderá ser de extrema valia, prevenindo a forma precoce e tardia da doença ${ }^{2,32}$.

Outra estratégia que também pode ser utilizada é a antissepsia do canal de parto, utilizando o gluconato de clorexidina, que é um antisséptico utilizado na prática hospitalar e ótimo redutor de bactérias Gram positivas. Esta é uma medida de baixo custo, simples e segura, no entanto, apesar de alguns estudos provarem sua eficácia, o CDC aguarda mais evidências científicas e somente recomenda o seu uso como medida profilática, se utilizada juntamente com a quimioprofilaxia $^{31}$.

Para a prevenção da infecção pelo EGB em neonatos, é recomendado à gestante que estiver colonizada pelo EGB ou que possuir fatores de riscos, fazer a quimioprofilaxia intraparto, logo após o início do trabalho de parto ou ruptura das membranas (bolsa amniótica). Muitos estudos mostram que a detecção no trato genital/anal do EGB, no período final da gestação, tem sido a conduta mais correta na prevenção da doença, na tentativa de assim, evitar uma possível complicação para criança e aumento dos custos para a maternidade ${ }^{31}$.

Esta quimioprofilaxia é realizada a partir da prescrição da penicilina $\mathrm{G}$, pois esta apresenta espectro estreito e provavelmente menor risco de causar resistência antimicrobiana. Em casos de alergia à penicilina, pode-se fazer o uso de cefazolina, clindamicina ou eritromicina, já nos casos em que o EGB se mostrar resistente, utiliza-se a vancomicina. A quimioprofilaxia requer uma atenção maior nos casos de internações repetidas por trabalho de parto prematuro, pois pode haver um uso abusivo de antibióticos, provocando o aumento de resistência frente aos antimicrobianos. No que diz respeito à cesárea eletiva, aquela realizada fora de trabalho de parto, a quimioprofilaxia não é recomendada. O uso de antibióticos seria capaz de evitar a infecção neonatal precoce, diminuindo assim, as taxas dessa doença em até $78 \%{ }^{32,33,34,35}$.

Estas medidas profiláticas visando à diminuição ou mesmo a eliminação do EGB em gestantes têm se mostrado eficazes, além disso, desenvolvimento de vacina também aponta para uma possibilidade de prevenção precoce e tardia da colonização por este agente bacteriano, no entanto, como principal medida ainda permanece a realização da pesquisa do EGB assim como preconizada, possibilitando a diminuição significativa dos casos desta infecção nas gestantes e consequentemente, as complicações ao concepto.

\section{Conclusão}

Diante dos artigos analisados, conclui-se que a colonização da gestante pelo EGB está intimamente associada ao parto prematuro e à possibilidade de ocorrência de infecções graves no recém-nascido. No Brasil, há uma escassez de informações relacionadas à prevalência destes micro-organismos nas gestantes, além das consequências associadas à infecção. Assim, é necessário ressaltar a importância de realizar a cultura de amostras vaginais e anais de gestantes entre a 35a e 37a semana de gestação durante o pré-natal, além de conhecer os fatores de risco associados à infecção, com destaque na relevância da adoção de medidas profiláticas direcionadas à redução da prevalência da infecção neonatal pelo Streptococcus agalactiae. A verificação dos casos e a análise das taxas de infecção materna poderão contribuir para adoção de medidas preventivas mais eficazes pelo sistema de saúde, possibilitando a diminuição das taxas de infecções em recémnascidos e, consequentemente a taxa de mortalidade neonatal ou mesmo de possíveis sequelas pós-natal associadas.

\section{Referências}

1. Gomes MJP. Gênero Streptococcus spp. Favet-Ufrgs. 2013; 1-76

2. Trabulsi LR, Alterthum F, editores.

3. Microbiologia 5a ed. São Paulo: 
Atheneu; 2008.

4. Gallo CBG. A importância do diagnóstico em gestantes colonizadas pelo Streptococcus do grupo beta na prevenção da doença neonatal. [Tese]. [São José do Rio Preto]: 2015. 15 p.

5. Murray PR, Baron EJ, Jorgensen JH, editors. Manual of Clinical Microbiology. 9a ed. Editora Asm Press; 2007.Centers For Disease Control And Prevention (CDC). Prevention of perinatal group B streptococcal disease: a public health perspective. 1996; MMWR Recomm Rep. 45(RR-7):1-24. Erratum in: MMWR Morb Mortal Wkly Rep. 1996; 45 (31): 679.

6. Vered H Eisenberg, David Raveh, Yair Meislish, Bernard Rudensky, Yossef Ezra, Arnon Samueloff, et al. Prevention of Early-Onset Neonatal Group B Streptococcal Infection: is Universal Screening by Culture Universally Applicable? Isr Med Assoc J. 2006. v. 8, n. 10, p. 698-702.

7. Pogere A, Zoccoli CM, Tobouti NR, Freitas PF, José d'Acampora A, Zunino JN. Prevalência da colonização pelo estreptococo do grupo B em gestantes atendidas no ambulatório de pré-natal. Rev. Bras. de Ginecol. Obstet. 2005; 27(4): 174-180.

8. Vaciloto $E$, Richtmann R, Costa HPF, Kusano EJU, Almeida MFB, Amaro ER. A survey of the incidence of neonatal sepsis by group $B$ Streptococcus during a decade in a Brazilian maternity hospital. Braz J Infect Dis. 2002;6(2):55-62.

9. Beraldo C, Brito ASJ, Saridakis HO, Matsuo T. Prevalência da colonização vaginal e anorretal por Estreptococo do grupo B em gestantes do terceiro trimestre. Rev Bras Ginec Obstet 2004; 26:543-9

10. Simões JA, Poletti GB, Portugal PM, Brolazo EM, Discacciati MG, Crema GD. Influência do Conteúdo vaginal de gestantes sobre a recuperação do estreptococo do grupo B nos meios de transporte Stuart e Amies. Rev. Bras. De Ginecol. Obstet. 2005; 27(11): 672-676

11. Filho D, Tibiriçá $S$, e Diniz C. Doença Perinatal associada aos estreptococos do Grupo B: aspectos clínico-microbiológicos e prevenção. HU Revista, 2008; 34(2), 127-134.

12. Costa ALR, Filho FL, Chein MBC, Brito LMO, Lamy ZC, Andrade KL. Prevalência de colonização por estreptococos do grupo B em gestantes atendidas em maternidade pública da região Nordeste do Brasil. Rev. Bras. De Ginecol. Obstet. 2008; 30(6):274-80.

13. Barbosa NG, Brito DVD, Reis $H$, Mantese OC, Pinhata MMM, Abdalla VOS, et al.
Colonização Materna Por Estreptococos Do Grupo B: Prevalência E Suscetibilidade Aos Antimicrobianos. Rev Pesq Saúde. Jan/abr. 2016; 13-16. 17(1): 13-16.

14. Higashi $A B$, SILVA IR, Goldman RE. Prevalência Do Estreptococo Do Grupo B Em Gestantes E Sua Relação Com a Infecção Neonatal. Rev Enferm Atenção Saúde. Jan/jul. 2016; 5(1), 23-35.

15. Nobre RA. Frequência de infecção por streptococcus b-hemolítico do grupo $B$ e outras bactérias em recém-nascidos com desconforto respiratório. Ribeirão Preto: Universidade de São Paulo; 1997

16. Miura E, Martin MC. Group B streptococcal neonatal infections in Rio Grande do Sul, Brazil. Rev Inst Med Trop Sao Paulo. 2001;43(5):243-6.

17. Pinheiro RS, Ferreira LCL, Brum IR, Guilherme JP, Monte RL. Estudo dos fatores de risco maternos associados à sepse neonatal precoce em hospital terciário da Amazônia brasileira. Rev Bras Ginecol Obstet. 2007;29(8):387-95.

18. Prefeitura do Município de São Paulo Secretaria Municipal da Saúde Áreas Técnicas da Saúde da Mulher e da Criança e Assistência Laboratorial. Prevenção da infecção neonatal pelo Streptococcus agalactiae (Estreptococo Grupo B ou GBS). [Citado 2008] Disponível em: http://www.prefeitura.sp.gov.br/cidade/secretar ias/upload/saude/arquivos/mulher/Prot estrept ococo B.pdf

19. Dias JF. Colonização por estreptococo do grupo B em gestantes em Cuiabá. [Tese]. Faculdade de Medicina da Universidade de São Paulo. Programa de pediatria, 2014. 85 p.

20. Centers For Disease Control And Prevention (CDC). Prevention of Perinatal Group B Streptococcal Disease: Revised Guidelines from CDC. [Citado 2010 Nov 19]. Disponível em: https://www.cdc.gov/mmwr/preview/mmwrhtm I/rr5910a1.htm

21. Rosa FM, Camacho ME, Rodriguez GJ, Liebana MC. Specimen storage in transport medium and detection of group B streptococci by culture. J Clin Microbiol. 2005;43:928-30.

22 Shet A, Ferrieri P. Neonatal \& maternal group B streptococcal infections: A comprehensive review. Indian J Med Res. 2004 Sep;120:141-150.

23. Schrag SJ, Zell ER, Lynfield R, Roome A, Arnold KE, Craig AS, et al. A population-based comparison of strategies to prevent early-onset 
group B streptococcal disease in neonates. $\mathrm{N} \mathrm{Engl}$ J Med 2002; 347(4):233-9.

24. Reiche EMV, Morimoto HK, Farias GN, Hisatsugu KR, Geller L, Gomes ACLF. et al. Prevalência de tripanossomíase americana, sífilis, toxoplasmose, rubéola, hepatite $B$, hepatite $C$ e da infecção pelo vírus da imunodeficiência humana, avaliada por intermédio de testes sorológicos, em gestantes atendidas no período de 1996 a 1998 no Hospital Universitário Regional Norte do Paraná (Universidade Estadual de Londrina, Paraná, Brasil). Rev Soc Bras Med Trop 2000; 33(6).

25. Koneman, EW, editores. Diagnóstico Microbiológico - Texto e Atlas colorido 6a. ed. Rio de Janeiro: Editora Guanabara Koogan; 2008.

26. Doran KS, Nizet V. Molecular pathogenesis of neonatal group B streptococcal infection: no longer in its infancy. Mol Microbiol. 2004; 54(1):23-31.

27. Silveira RC, Procianoy RS. Uma revisão atual sobre Sepse Neonatal. Boletim Científico de Pediatria. 2012, v. 1, n.1.

28. Feijó EJ, Barreto EA, Silva MHA, Correa RCA, Carvalho TC, Ventura WP. Sepse Neonatal: Revisão Sistemática da Literatura. 2013; Univ. Rev de Trab Acadêmicos, v.4 n.6.

29. Afroza S. Neonatal sepsis - a global problem: an overview. Mymensingh Medical Journal. 2006; 15(1):108-14.

30. Ministério Da Saúde Brasil. Atenção à Saúde do Recém-Nascido. [Citado em 2011]. Disponivel em: http://www.redeblh.fiocruz.br/media/arn v1.pdf 31. Costa HPF. Prevenção da Doença Perinatal Pelo Estreptococo do Grupo B [Tese]. [São Paulo]: Membro do Departamento de Neonatologia da SBP e da SPSP. Mestre em Pediatria pela UNIFESP; 2011. 18 p.

32. Centers For Disease Control And Prevention (CDC). Morbidity and Mortality Weekly Report, Prevention of Perinatal Group B Streptococcal Disease Revised Guidelines from. 2002; 51: 1-24.

33. Schrag $S$, Gowitz R, Fultz-Butts K, Schuchat A. Prevention of Perinatal Group B Streptococcal Disease: Revised Guidelines from CDC. MMWR Recomm Rep. 2002 16;51(RR-11):122.

34. Turow J, Spitzer AR. Group B streptococcal infection early onset disease controversies in prevention guidelines, and management strategies for the neonate. Clin Pediatr (Phila). 2000; 39: 317-326.
35. Stoll BJ, Hansen N, Fanaroff AA, Wright LL, Carlo WA, Ehrenkranz RA, et al. Changes in pathogens causing early -onset sepsis in verylow-birth-weight infants. $\mathrm{N}$ Engl J Med. 2002 Jul 25;347(4):240-7.

\section{Endereço para Correspondência}

Pontifícia Universidade Católica de Goiás - PUC

134, R. 235, 76 - Setor Leste Universitário, Goiânia - GO

e-mail: $\underline{\text { tamara-dayse@hotmail.com }}$

Recebido em 26/06/2017

Aprovado em 09/11/2017

Publicado em 01/12/2017 